\title{
THE ANTECEDENTS OF INDIVIDUAL INVESTMENT BEHAVIOR: MATERIALISM, RISK AVERSION, POSITIVE AND NEGATIVE AFFECTS
}

\author{
DOI: 10.17261/Pressacademia.2018.851 \\ PAP- V.7-2018(4)-p.24-30
}

\section{Pelin Kanten ${ }^{1}$, Bahar Girgin ${ }^{2}$, Emre Kurt ${ }^{3}$}

${ }^{1}$ Canakkale Onsekiz Mart University, Faculty of Political Science, Canakkale, Turkey. pelinkanten@comu.edu.tr, ORCID: 0000-0002-6487-0203

${ }^{2}$ Canakkale Onsekiz Mart University, Faculty of Political Science, Cnakkale, Turkey. erman_girgin@hotmail.com, ORCID: 0000-0003-4935-6633

${ }^{3}$ Canakkale Onsekiz Mart University, Faculty of Political Science, Canakkale, Turkey. emrekurt2016@gmail.com, ORCID: 0000-0002-4170-8553

To cite this document

Kanten, P., Girgin, B., Kurt, E. (2018). The antecedents of individual investment behavior: materialism, risk aversion, positive and negative affects. PressAcademia Procedia (PAP), V.7, p.24-30.

Permemant link to this document: $h$ ttp://doi.org/10.17261/Pressacademia.2018.851

Copyright: Published by PressAcademia and limited licenced re-use rights only.

\section{ABSTRACT}

Purpose- This study aims to investigate some of the antecedents of individuals' investment behaviors. In the literature, it is seen studies suggest that some individual factors have a significant effect on investment decisions of individuals. Therefore, materialism, risk aversion, positive and negative affects are considered as predictors of individual investment decisions within the scope of the study.

Methodology- For this purpose, the data which were collected from 169 individuals who work in different industries such as health, automotive, retailing and finance by the survey method were analyzed using the structural equation modeling.

Findings- The results of the study indicate that risk aversion has a positive and significant effect on individuals' investment decisions. However, materialism, positive and negative affect have no significant effect on individuals' investment decisions.

Conclusion- On the other hand, it was revealed that individuals' investment behavior differ according to their monthly income.

Keywords: Investment behavior, materialism, affects, risk aversion

JEL Codes: M10, M20, M54

\section{INTRODUCTION}

Nowadays, the financial services sector considered as the most crucial area which offers the investors a wide range of investment choices. Some of the investment choices are marketable and liquid while others non-marketable and illiquid. In this context, the investors choose investment options depending on their needs, risk of investment and earnings that will be expected (Perera, 2016: 4). Generally, from the investors' perspective investment options can be classified as economic and financial investment. While economic investments refers to the purchasing physical assets such as building, parcel of land or equipment; financial investment regarded as to choice financial instruments like shares, securities, mutual funds, foreign currency and etc. (Shafi, 2014: 61). Due to the investment options lead individuals to obtain high profit or heavy losses, investment decision-making evaluated as a fundamental process. Therefore, it is needed to reveal the factors which affect investors' decisions or choice of options. In literature, it is seen that some economical and psychological factors affecting individual's investment behaviors (Sarwar and Asaf, 2016: 2). On the other hand, researchers asserted that it is crucial to take psychological, sociological and demographic factors into account to explore the major attributes of how investors behave. Regarding the psychological factor, it is emphasized that risk aversion, risk tolerance anchoring bias, affects and overconfidence are significant antecedents of individuals' investment behavior (Mak and Ip, 2017). In this context, this study aims to examine some of the psychological antecedents of individual investment behavior which are labeled as specific personality trait as a materialism, positive and negative affects and risk aversion in different industries like health, retailing, automotive and finance. However, there is no any research in the existing literature yet examining the relationships among materialism, affects, risk aversion and individual investment behavior in together. Consequently, this study aims to investigate the individual antecedents of investment behaviors, so it attempts to add contribution to the literature. 


\section{THEORETICAL FRAMEWORK AND HYPOTHESES DEVELOPMENT}

Individual investment behavior can be conceptualized as the choices about purchases of small amounts of securities for individuals own account (Nofsinger and Richard, 2002). In literature, it is seen that economists, sociologists and psychologists have all attempted to explain individual investor behavior in various ways. For example, economists have focused largely on the "rationality" or "irrationality" of the investors decisions. In addition, sociologists explain investment behaviors by focusing on the individuals' social environments and psychologists trying to clarify individual investment behavior by focusing on individual characteristics (Shafi, 2014: 61). In other words, individual investment behavior refers to the how the investors judge, predict, analyze and review the procedures for decision making that includes investment psychology, information gathering, understanding, research and analysis financial issues. This behavior requires making the rational decisions for maximizing investors returns based on the information available by taking judgments that are free from their emotions (Shikuku, 2014: 9). Therefore, it is assumed that investors to be rational for maximizing their wealthness and they have to decide investment strategies for taking in consideration risk-return (Jagongo and Mutswenje, 2014: 92). However, it is suggested that individual investment behavior is based on the both rational factors and also psychological ones. Psychological factors are considered as a significant components which have a crucial effect on individuals' attitudes and behaviors related with the investment decisions. For example, when individuals are in good mood or have positive affects, they become more optimistic in their financial judgments, in case they have negative affects predominantly, it is expected that they will be more pessimistic (Phan and Zhou, 2014: 77). Psychological factors refers to the moods, affects, thoughts, feelings and the other cognitive traits which effects the behaviors and attitudes of investors. These factors also represent the individuals' determinant characteristics or personality traits which cause to influence financial decisions or investment behaviors (Sarwar and Afaf, 2016: 2). In this study, from the psychological perspective, materialistic personality trait, positive and negative affect and risk aversion have been examined.

Materialism is defined as a personal value which reflects the individuals' belief about the importance of possessions in their lives (Likitapiwat et al., 2015: 110). It is characterized as a set of values and goals that individuals place emphasis on such as wealth, status, image and properties (Hui and Tsang, 2017: 174). Due to the materialism represent the one of the complex personality traits, it is expected that may affect the individuals' choices, preferences, decisions and behaviors in various situations (Górnik-Durose and Pilch, 2016: 102). For example, Donnelly et al. $(2012,2013)$ asserted that materialistic individuals who place wealth, property and status to forefront, they are more prone to lose money and making wrong decisions about money management. However, it is suggested that materialistic individuals may have a positive tendency to consume at high rates and also they are inclined to be less thrifty and to contract a debt (Kasser, 2016: 494). Therefore, it is possible to express that materialistic personality may have a significant effect on individual's attitudes and behaviors related with the financial issues, so the following hypothesis are proposed:

$\mathrm{H}_{1}$ : Materialism influences individuals' investment behaviors.

Regarding the psychological factor, it is emphasized that risk tolerance, anchoring bias, overconfidence, affects and risk aversion are significant antecedents of individuals' investment behavior (Mak and Ip, 2017). Risk aversion refers to the avoidance of individuals to make investment which will give them loss. In other words, while some of the individuals like to take risk or have a risk capacity to handle them, others may desire to keep down their financial investments and not tend to take a risk. Accordingly, it can be expressed that individuals who have a risk aversion characteristic, they will invest small securities which includes low risk and low profit. On the other hand, it is suggested that moods and affects lead to influence investors' investment decision. For instance, when individuals have positive feelings in every sphere of their life, they may exhibit more optimistic behaviors related to their investment decisions (Sarwar and Afaf, 2016: 3-4). Abass and Dar Fayaz (2013) indicated that individuals' emotions are the vital components which lead to investors in a positive or negative way while they make an investment decisions. In this context, it is expected that individuals' positive and negative affects may have a significant effect on the investment behaviors, thus the following hypotheses are proposed:

$\mathrm{H}_{2}$ : Risk aversion influences individuals' investment behaviors.

$\mathrm{H}_{3}$ : Positive affect influences individuals' investment behaviors

$\mathrm{H}_{4}$ : Negative affect influences individuals' investment behaviors.

When we examined relevant literature, it can be concluded that there are numerous antecedents of individual investor's behaviors. While some factors influence majorly, others may have slight role in influencing the individual investment behaviors, so it is seen that these factors can be grouped into demographic, economic, social, and psychological in general (Shafi, 2014: 66). According to this classification, it is expected that demographic factors such as age, gender, income, education and working experience may influence the individual investment behaviors (Vijaya, 2014: 43). Gunay and Demirel (2011); Geetha and Ramesh (2012) revealed that there is a relationship between demographic factors and individuals' investment decisions. However, Al-Tamimi and Kalli (2009) emphasized that financial decisions affected individual's income and education level and workplace activity. Kaleem et al., (2009) asserted that individuals' investment decisions were affected from their income and education levels and their ages. Therefore, the following hypothesis are proposed:

$\mathrm{H}_{5}$ : Investment behaviors differ depending on the individuals' monthly income. 
Figure 1: Research Model

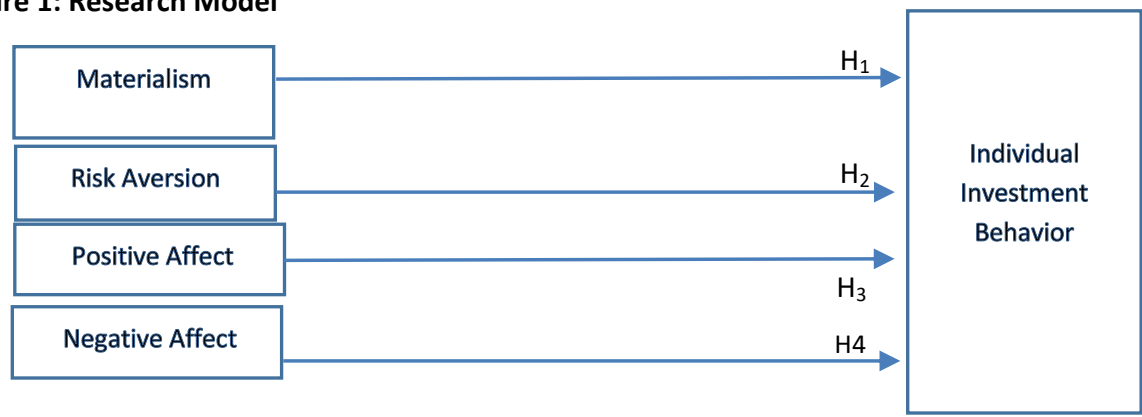

\section{RESEARCH METHODOLOGY}

\subsection{Sample and Procedures}

The sample of the present research was composed of 169 individuals who have been working in different industries such as health, automotive, retailing and finance determined via convenient sampling method. Out of 250 questionnaires that have been sent out, 190 have been returned, representing a response rate of $76 \%$. After the elimination of the cases that have incomplete data and outliers, 169 questionnaires (67\%) have been accepted as valid and included in the evaluations. However, questionnaire survey method is used for data collection in this study. The questionnaire form contains four different measures related to research variables.

\subsection{Measures}

The measures used in the questionnaire forms have been adapted from the previous studies in the literature. All measures have been adapted to Turkish by the lecturers and a pilot study has been conducted for the validity of these measures. Before the distribution of the survey to the actual sample, a pilot study was conducted in order to determine whether the questions would be understood properly and to check the reliability of the scales. As a result of the pilot study, some corrections were made in the questionnaire forms. A Likert-type metric, that is, expressions with five intervals has been used for answers to the statements of survey. Anchored such; "1- strongly disagree, 2- disagree, 3- agree or not agree, 4- agree, 5-strongly agree". Moreover, 7 demographic questions were included in the questionnaire form. Firstly, all scales were subjected to the exploratory factor analyses to check the dimensions, and then confirmatory factor analyses were applied to all scales.

- Individual Investment Behavior Scale: Individual investment behavior levels were measured with 10 items from Mayfield et al. (2008) study. Exploratory factor analyses using principle component analysis with varimax rotation was applied to the adapted scale to check the dimensions. As a result of the varimax rotation of the data related to the individual investment behavior scale variables, 4 items were removed from the analysis due to the factor loading under 0.50 . Additionally, two factor solutions; (short-term investment intention and long-term investment intention) were obtained in accordance with the theoretical structure. Some examples of the items asked to the employees are as follows: "I intend to put at least half of my investment money into the stock market"; "I intend to save at least $10 \%$ of my gross earnings for investing/saving/retirement purposes". Factor loadings of the items ranged from .56 to .86. The Cronbach's alpha coefficient of the individual investment behavior scale items is .75 .

- Materialism Scale: Individuals' materialism levels were measured with 23 items which was developed by Trinh and Phau (2012). Exploratory factor analyses using principle component analysis with varimax rotation was applied to the adapted scale to check the dimensions. As a result of the varimax rotation of the data related to the materialism scale variables, 10 items were removed from the analysis due to the factor loading under 0.50. Additionally, three factor solutions; (success; distinctiveness; essentiality \& happiness) were obtained in accordance with the theoretical structure. Some examples of the items asked to the employees are as follows: "Material possessions are important because they contribute a lot to my happiness"; "I like to own expensive things than most people because this is a sign of success". Factor loadings of the items ranged from .55 to .85 . The Cronbach's alpha coefficient of the materialism scale items is 81 .

- Risk Aversion Scale: Individuals' risk aversion levels were measured with 4 items from Mayfield et al. (2008) study. Exploratory factor analyses using principle component analysis with varimax rotation was applied to the adapted scale to check the dimensions. As a result of the exploratory factor analysis of the data related to the risk aversion, one factor solution obtained in accordance with the theoretical structure. Some examples of the items are as follows: "I am not willing to take risk when choosing a stock or investment". Factor loadings of the items ranged from .79 to .89 . The Cronbach's alpha coefficient of the risk aversion scale items is .76.

- Positive and Negative Affect (PANAS) Scale: Individuals' positive and negative affect levels were measured with 20 items brief scale developed by Watson et al (1998). As a result of the varimax rotation of the data related to the PANAS scale variables, 8 items were removed from the analysis due to the factor loading under 0.50. Additionally, two factor solutions; (positive affect and negative affect) were obtained in accordance with the theoretical structure. Example items include; "I am strong", "I am nervous". Factor loadings of the items ranged from .57 to .87 . The Cronbach's alpha coefficient of the positive and negative affect scale items is .71.

After the exploratory factor analyses, the confirmatory factor analysis has been conducted by Lisrel 8.8 for all scales. Goodness of fit indexes is presented in Table 1. It can be seen that all of the fit indexes fall within the acceptable ranges (Schermelleh-Engel et al., 2003: 52; Meydan and Şeşen, 2011: 35). 
Table 1: Goodness of Fit Indexes of the Scales

\begin{tabular}{lccccccccc}
\hline Variables & $\chi^{\mathbf{2}}$ & df. & $\begin{array}{l}\chi^{2} / \mathbf{d f} \\
\leq \mathbf{5}\end{array}$ & $\begin{array}{l}\text { GFI } \\
\geq \mathbf{8 5}\end{array}$ & $\begin{array}{l}\text { AGFI } \\
\geq .80\end{array}$ & $\begin{array}{l}\text { CFI } \\
\geq .90\end{array}$ & $\begin{array}{l}\text { IFI } \\
\geq .90\end{array}$ & $\begin{array}{l}\text { NNFI } \\
\geq .90\end{array}$ & $\begin{array}{l}\text { RMSEA } \\
\leq \mathbf{0 . 0 8}\end{array}$ \\
\hline Materialism & 66.31 & 50 & 1.32 & 0.94 & 0.90 & 0.99 & 0.99 & 0.98 & 0.044 \\
\hline Risk Aversion & 0.00 & 0 & 0.00 & 1.00 & 1.00 & 1.00 & 1.00 & 1.00 & 0.000 \\
\hline Positive/Negative Affect & 20.33 & 12 & 1.69 & 0.95 & 0.90 & 0.93 & 0.90 & 0.90 & 0.064 \\
\hline Ind.Investment Behavior & 26.25 & 8 & 3.28 & 0.95 & 0.88 & 0.90 & 0.90 & 0.91 & 0.063 \\
\hline
\end{tabular}

\subsection{Data Analysis}

SPSS for Windows 20.0 and Lisrel 8.80 programs were used to analyze the obtained data. After the exploratory and confirmatory analysis, descriptive statistics such as means, standard deviations and pearson correlation analysis of the study variables were examined. Following that, structural equation model was used to test all research hypotheses.

\section{RESEARCH FINDINGS}

\subsection{Respondent Profile}

$56 \%$ of the individuals' were female and $44 \%$ were male. $44 \%$ of the individuals were between the ages $30-39,33 \%$ of them below than 30 . $23 \%$ of the individuals older than 40 . In terms of education level, $33 \%$ had a bachelor's degree, $22 \%$ had a high school education, $\% 22$ of them had a vocational school degree, and \% 18 of the individuals had graduate degree and \%5 had a primary education level. Analysis of the working industries showed that, majority $(66 \%)$ of the individuals had been working in private sector such as finance, automotive and retailing, $24 \%$ of them in health sector both in public and private institutions and $10 \%$ of the individuals working as a storekeeper. $64 \%$ of the participants had been working for between $5-20$ years and $17 \%$ of them have been working for less than 1 year, while $19 \%$ of them had been working for more than 20 years in the same sector.

\subsection{Descriptive Analyses}

In the scope of the descriptive analyses means, standard deviations and correlations have been conducted which are related to materialism, risk aversion, positive and negative affect and individual investment behavior. The values are given in Table 2 .

Table 2. Means, Standard Deviations and Correlations of the Study Variables

\begin{tabular}{lccccccccc}
\hline & Mean. & S.S & 1 & 2 & 3 & 4 & 5 \\
\hline Materialism & 2.67 & .69 & 1 & & & & & & \\
Risk Aversion & 2.30 & .99 & .048 & 1 & & & & \\
Positive Affect & 2.08 & .76 & $.262^{* *}$ & $.041^{* *}$ & 1 & & & \\
Negative Affect & 3.66 & .77 & .085 & .033 &.$-206^{* *}$ & 1 & & \\
Ind.Investment Behavior & 3.20 & .86 & .075 & $.258^{* *}$ & -.063 & .150 & 1 & \\
\hline
\end{tabular}

As can be seen in Table 2, the results of correlation analysis shows that risk aversion $(r=.258, p<0.01)$ positively related to the individuals' investment behavior. However, there is no significant relationship between materialism, positive/negative affect and individuals' investment behavior.

\subsection{Measurement Model}

For the verification of the model two step approaches by Anderson and Gerbing (1988) has been used. According to this approach, prior to testing the hypothesized structural model, firstly the research model needs to be tested to reach a sufficient goodness of fit indexes. After obtaining acceptable indexes it can be proceed with the structural model. The results of the measurement model were; $x^{2}: 518.93$; df: 348 ; $\mathrm{x}^{2}$ / df; 1.49; RMSEA: 0.050; GFI: 0.85; IFI: 0.96; CFI: 0.95; NFI: 0.94; NNFI: 0.95. These values indicate that measurement model has been acceptable (Schermelleh-Engel et al., 2003: 52; Meydan and Şeşen, 2011: 37).

\subsection{Structural Equation Model}

After the measurement model was demonstrated as acceptable, the structural equation model was applied to verify hypotheses for the causal relationships in the research model. The results of the structural equation model were; $x^{2}: 272.49 ; d f: 216 ; x^{2} / d f: 1.26$; RMSEA: 0.039; GFI: 0.88; CFI: 0.94; IFI: 0.94; NFI: 0.93; NNFI: 0.94. These results indicate that structural model has been acceptable (SchermellehEngel et al., 2003: 52; Meydan and Şeşen, 2011: 37). According to the results of structural equation model, the path parameter and significance levels show that risk aversion $(\gamma=0.25$; $t$-value $=2.08)$ has a positive and significant effect on individuals' investment behavior. However, materialism $(\gamma=0.39$; $\mathrm{t}$-value $=0.64)$; has no significant effect on individuals' investment behavior. On the other hand positive $(\gamma=-$ 0.22 ; t-value=-0.05); and negative affect $(\gamma=0.37$; $\mathrm{t}$-value $=0.25)$; have no significant effect on individuals' investment behavior; so $\mathrm{H}_{1}, \mathrm{H}_{3}$ and $\mathrm{H}_{4}$ hypotheses are not supported. In this regard, it can be expressed that risk aversion can be considered as antecedents of individuals' investment behaviors, so $\mathrm{H}_{2}$ hypothesis is supported. 
Figure 2: Structural Model And Path Coefficients

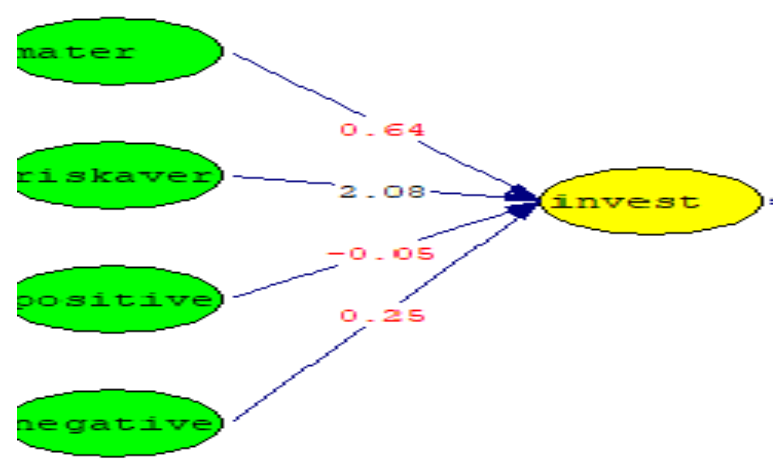

mater: Materialism

riskaver: Risk Aversion

Positive: Positive Affect

Negative: Negative Affect

Invest: Investment Behavior

\subsection{Anova Test}

Anova test were applied to determine individuals' investment behavior levels differ according to their monthly income.

Table 3: Anova Test for the Monthly Income

\begin{tabular}{|l|l|l|l|l|}
\hline Investment Behavior & Sum of Squares & df & F & Sig. \\
\hline Between Groups & 9.960 & 4 & \multirow{2}{*}{3.552} & \multirow{2}{*}{.008* $^{*}$} \\
\hline Within Groups & 114.957 & 164 & & \\
\hline Total & 124.917 & 168 & & \\
\hline
\end{tabular}

According to the results of the anova test, the significance levels show that inviduals' investment behavior levels differ related with their monthly income so $\mathrm{H}_{5}$ hypothesis was supported. Therefore, it can be inferred that individuals determine which investment tools they will choose according to their total monthly income. In other words, total monthly income also regarded as an indicative component of long and short term investment decisions.

\section{CONCLUSION}

For the individuals maintaining their' life successfully, investment decision-making is very important factor due to it brings high earnings or financial loss. To cope with these heavy losses or sustain financial success, individuals need to give their decisions rationally and also should be aware of the factors which affects investment decisions. Due to the investors do not give their decisions in rationality and also they have weaknesses such as cognitive, emotional, overconfidence and biases, it is needed to examine predominating role of individual antecedents of investment behaviors. From the previous studies, it is seen that various antecedents influence the individual investment behaviors. However, while some of the antecedents effect majorly investment behaviors, others have a minor role on the financial decisions so it can be said that these antecedents cause to the right or wrong investment choices of individuals. Therefore, individuals need to coordinate, regulate and manage of these antecedents for providing rational choices in their investment decisions. In the literature, it is seen that these antecedents grouped under the different dimensions such as demographic, economic, social and psychological. In this study, from the psychological perspective materialism, positive and negative affect and risk aversion has been evaluated scope of the antecedents. Moreover, in the context of demographical factors, only monthly income of the individuals has been examined.

As a result of the research findings, it has been obtained that from the psychological factors, merely risk aversion has a significant and positive effect on individuals' investment behaviors so $\mathrm{H}_{2}$ was supported. On the other hand, materialistic personality, positive and negative affect have no significant effect on the investment behaviors, thus $H_{1}, H_{3}$ and $H_{4}$ were not supported. Besides, from the demographical factors, it is found that individuals' investment behaviors differ related to their mothly income of individuals and $\mathrm{H}_{5}$ hypothesis was supported. This result shows that monthly income can be considered as a crucial economic component which determines the financial decisions of individuals. However, it can be said that individuals investment behaviors has not affected from their characteristics such as focusing on profit, success, gain and property and affects. Nevertheless, risk aversion which shows the level of avoidance from the uncertainty lead individuals to make right choices under the changeable conditions. For example, risk aversion make easier individuals to venture to the investment instruments such as bonds, stocks, gold and foreign exchange in order to secure the future lives. That is to say, individuals who tend to risk aversion may be much more interested in to make right investment decisions. Consequently, as a scope of the research results, it is possible to express that risk aversion which represents one of the important personality trait and economic status of individuals have considered as an antecedents of investment behaviors.

In the literature, it is seen that some studies were examined various antecedents of individual investment behaviors like overconfidence, biases, emotions, goals, desires, personality traits, risk aversion, age, education and income levels and etc. Accordingly, this study aims to add several contributions to the theory by exploring the relationships among materialism, risk aversion, positive and negative affect variables and determining the antecedents of individual investment behaviors. Moreover, this study emphasizes which components have a 
significant effect on investment decisions and lead brokers to take consider these effective components of investment behaviors. In other words, agents, brokers and financial institutions need to learn investor's personality profile for to guide them to the right and rational investment decisions. Because, investment decisions highly dependent to the investors distinct personality trait and their economic conditions. For future studies, it is recommended that the research model can be tested with larger samples or on entrepreneurs who make a crucial and profitable investments and the results can be compared. On the other hand, the research model can be redesigned by including some other variables in consideration of antecedents of individual investment behaviors. For instance, goals and desires of investors, age, gender, culture and personal values can be investigated.

\section{REFERENCES}

Abass, B. M., Dar Fayaz, A. (2013). An empirical study to know the role of emotions in individual investment behavior. ZENITH International Journal of Business Economics \& Management Research, Vol.3, No. 2.

Al-Tamimi, H., Kalli, A. A. B. (2009). Financial literacy and investment decisions of UAE investors. The Journal of Risk Finance, Vol. 10, No. 5, p. $500-516$

Donnelly, G., Iyer, R., Howell, R, T. (2012). The Big Five personality traits, material values, and financial well-being of self-described money managers. J. Econ. Psychol, 33, p.1129-1142.

Donnelly, G., Ksendzova, M., Howell, R. T. (2013). Sadness, identity, and plastic in over-shopping: the interplay of materialism, poor credit management, and emotional buying motives in predicting compulsive consumption. J. Econ. Psychol, 39, p.113-125.

Geetha, N., Ramesh, M. (2012). A study on relevance of demographic factors in investment decisions. International Journal of Financial Management, Vol.1, No.1, p. 39-56.

Górnik-Durose, M. E., Pilch, I. (2016). The dual nature of materialism. How personality shapes materialistic value orientation. Journal of Economic Psychology, 57, p. 102-116.

Gunay, S., Demirel, E. (2011). Interaction between demographic and financial behavior factors in terms of investment decision making. International Research Journal of Finance and Economics, 66, p.147-156.

Jagongo, A., Mutswenje, V. S. (2014). A survey of the factors influencing investment decisions: the case of individual investors at the NSE. International Journal of Humanities and Social Science, Vol. 4, No. 4, p. 92-102.

Hui, C., Tsang, O. (2017). The role of materialism in self-disclosure within close relationships. Personality and Individual Differences, 111, p. 174-177.

Islamoğlu, M., Apan, M., Ayvali, A. (2015). Determination of factors affecting individual investor behaviours: a study on bankers. International Journal of Economics and Financial, 5(2), p.531-543.

Kaleem, A., Wajid, R. A., Hussain, H. S. (2009). Factors affecting financial advisor's perception in portfolio management: with reference to Pakistan. Oxford Business and Economics Conference, June 24-26.

Kasser, T. (2016). Materialistic values and goals. Annu. Rev. Psychol, 67, p. 489-514.

Likitapiwat, T., Sereetrakul, W., Wichadee, S. (2015). Examining materialistic values of university students in Thailand Examine de Los Valores Materialistas de Estudiantes Universitarios en Tailandia. International Journal of Psychological Research, Vol. 8, No.1, p. 109-118.

Mak, M. K., Ip, W. (2017). An exploratory study of investment behavior of investors. International Journal of Engineering Business Management, Vol. 9, p.1-12.

Mayfield, C., Perdue, G., Wooten, K. (2008). Investment management and personality type. Financial Services Review, 17, p. 219-236.

Meydan, C. H., Şeşen, H. (2011). Yapısal eşitlik modellemesi AMOS uygulamaları. Ankara: Detay Yayıncılık.

Nofsinger, Richard (2002). Individual investments behaviour. New York, McGraw-Hill.

Perera, A. M. (2016). Gender attitudes and investor behaviour: evidence from individual investors in North Western province. Sri Lanka Journal of Economic Research, Vol. 4, No. 1, p. 3-17.

Phan, K., Zhou, J. (2014). American journal of business and management. Vol. 3, No. 2, p. 77-94.

Sarwar, A., Afaf, G. (2016). A comparison between psychological and economic factors affecting individual investor's decision making behavior. Cogent Business \& Management, 3, p. 1-18.

Schermelleh-Engel, K., Moosbrugger, H., Müller, H. (2003). Evaluating the fit of structural equation models: tests of significance and descriptive goodness-of-fit measures. Methods of Psychological Research, 8 (2), 23-74.

Shafi, M. (2014). Determinants influencing individual investor behavior in stock market: a cross country research survey. Arabian Journal of Business and Management Review, Vol. 2, No. 1, p. 60-71.

Shikuku, O. C. (2014). The effect of behavioral factors on individual investor choices at the Nairobi securities exchange. Degree of Master of Science in Finance in the School of Business, University of Nairobi. 
Trinh, V. D., Phau, I. (2012). A new set of measurements for the materialism scale. ANZMAC Annual Conference Proceedings. University of South Australia. Australia: 1-7.

Watson, D., Clark, L. A., Tellegen, A. (1998). Development and validation of brief measures of positive and negative affect: the PANAS scales. Journal of Personality and Social Psychology, Vol. 54, No. 6, p. 1063-1070.

Vijaya, E. (2014). Influential factors on investment behavior of individual investors: a review of empirical evidences from various countries. International Research Journal of Management and Commerce, Vol. 1, No. 5, p. 35-46. 